Article

\title{
Effects of an Alkalizing or Acidizing Diet on High-Intensity Exercise Performance under Normoxic and Hypoxic Conditions in Physically Active Adults: A Randomized, Crossover Trial
}

\author{
Mirjam Limmer ${ }^{1,2, *} \mathbb{C}$, Juliane Sonntag ${ }^{2}$, Markus de Marées ${ }^{1}$ and Petra Platen ${ }^{1}(\mathbb{C}$ \\ 1 Department of Sports Medicine \& Sports Nutrition, Ruhr-University Bochum, Gesundheitscampus Nord 10, \\ 44801 Bochum, Germany; markus.demarees@rub.de (M.d.M.); petra.platen@rub.de (P.P.) \\ 2 Institute of Outdoor Sports and Environmental Science, German Sport University Cologne, 50933 Cologne, \\ Germany; jule.sonntag@yahoo.de \\ * Correspondence: mirjam.limmer@rub.de
}

Received: 19 January 2020; Accepted: 2 March 2020; Published: 4 March 2020

\begin{abstract}
Pre-alkalization caused by dietary supplements such as sodium bicarbonate improves anaerobic exercise performance. However, the influence of a base-forming nutrition on anaerobic performance in hypoxia remains unknown. Herein, we investigated the effects of an alkalizing or acidizing diet on high-intensity performance and associated metabolic parameters in normoxia and hypoxia. In a randomized crossover design, 15 participants ( $24.5 \pm 3.9$ years old) performed two trials following four days of either an alkalizing (BASE) or an acidizing (ACID) diet in normoxia. Subsequently, participants performed two trials (BASE; ACID) after $12 \mathrm{~h}$ of normobaric hypoxic exposure. Anaerobic exercise performance was assessed using the portable tethered sprint running (PTSR) test. PTSR assessed overall peak force, mean force, and fatigue index. Blood lactate levels, blood gas parameters, heart rate, and rate of perceived exertion were assessed post-PTSR. Urinary $\mathrm{pH}$ was analyzed daily. There were no differences between BASE and ACID conditions for any of the PTSR-related parameters. However, urinary $\mathrm{pH}$, blood $\mathrm{pH}$, blood bicarbonate concentration, and base excess were significantly higher in BASE compared with ACID $(p<0.001)$. These findings show a diet-induced increase in blood buffer capacity, represented by blood bicarbonate concentration and base excess. However, diet-induced metabolic changes did not improve PTSR-related anaerobic performance.
\end{abstract}

Keywords: acid-base balance; potential renal acid load (PRAL); base-forming nutrition; acid-forming nutrition; moderate simulated altitude; hypoxic chamber; sports nutrition; mountain sport disciplines; anaerobic exercise test

\section{Introduction}

Many sport competitions staged at terrestrial altitudes ranging up to $3500 \mathrm{~m}$ (e.g., track-and-field, cycling and team sport events, cross-country or alpine ski races, and mountain biking challenges) often require single or multiple bouts of high-intensity, anaerobic exercise performance [1-5]. In addition, although insufficiently investigated to date, several mountaineering disciplines are performed at moderate to high altitudes with high anaerobic demands (e.g., ski touring, and single- or multi-pitch rock, mixed, or ice climbing) [6,7].

However, acute exposure to moderate and high altitudes above $1500 \mathrm{~m}$ can impair anaerobic exercise performance [8]. Reduced exercise tolerance above the lactate threshold at altitude is mainly caused by severe disruption to homeostasis resulting from a decline in arterial oxygen saturation 
$\left(\mathrm{S}_{\mathrm{a}} \mathrm{O}_{2}\right)$ because of reduced oxygen pressure in the ambient and inspired air $\left(\mathrm{P}_{\mathrm{I}} \mathrm{O}_{2}\right)$ [9]. The reduced $\mathrm{P}_{\mathrm{I}} \mathrm{O}_{2}$ leads to a decrease in arterial oxygen partial pressure $\left(\mathrm{PO}_{2}\right)$ and to hypoxemia, which stimulates the peripheral chemoreceptors to evoke $\mathrm{CO}_{2}$ washout [10-12]. Concurrently, hyperventilation occurs as a hypoxic ventilatory response during acclimatization to high altitude, while carbon dioxide partial pressure $\left(\mathrm{PCO}_{2}\right)$ falls and arterial $\mathrm{pH}$ increases according to the Henderson-Hasselbalch equation $[10,13,14]$. This respiratory alkalosis is subsequently compensated for by the increased renal elimination of bicarbonate ions $\left(\left[\mathrm{HCO}_{3}{ }^{-}\right]\right)$, which results in a decrease in blood $\left[\mathrm{HCO}_{3}{ }^{-}\right]$and an arterial $\mathrm{pH}$ returning to normal $[10,11,13]$. Blood $\left[\mathrm{HCO}_{3}{ }^{-}\right]$is an essential blood buffer for metabolic acids. During maximal workloads with blood lactate levels up to $15 \mathrm{mmol} / \mathrm{L}$, there is a corresponding decrease in plasma $\left[\mathrm{HCO}_{3}{ }^{-}\right]$[15]. Thus, the resulting decline in $\left[\mathrm{HCO}_{3}{ }^{-}\right]$and blood buffer capacity in the course of altitude adaption may significantly affect anaerobic exercise performance at altitude, particularly above the lactate threshold [10,16-19].

Regarding anaerobic exercise performance at altitude, several studies have investigated the effects of acute hypoxia on anaerobic performance parameters [20-25]. However, there are inconsistent and controversial findings, with reports of either a significant impairment [20-25] or unaffected [26-29] anaerobic exercise performance when exposed to acute hypoxia. Considering the applied study protocols, this inconsistent and often unaffected anaerobic exercise performance may relate to the lack of conformity in the duration of exposure to hypoxic conditions prior to exercise. Metabolic compensation of respiratory alkalosis and the associated $\left[\mathrm{HCO}_{3}{ }^{-}\right]$loss is considered a slow-adapting mechanism. For example, progression after $6 \mathrm{~h}$ and completion after $24 \mathrm{~h}$ of low to moderate altitude exposure was reported $[10,30]$. Furthermore, this process was reported to remain incomplete after $24 \mathrm{~h}$ of exposure to high altitude, but was completed after some days [10,12,30,31].

However, pre-exercise exposure to hypoxia within these studies investigating anaerobic exercise performance at simulated altitudes mainly ranged between $15 \mathrm{~min}$ and $1 \mathrm{~h}$ [20-22,24,32]. Thus, we suggest that this short exposure to simulated hypoxic conditions does not reflect the time course of renal compensation of hypoxia-induced respiratory alkalosis, and is inappropriate for assessing decreases in anaerobic exercise performance because of the metabolic compensation of respiratory alkalosis and the associated $\left[\mathrm{HCO}_{3}{ }^{-}\right]$loss. Additionally, recent studies reporting no impairment of anaerobic exercise performance mainly used 30-s and 45-s Wingate tests to assess anaerobic exercise performance [26-29], despite the evidence that short duration, high-intensity exercise performance can be maintained in acute hypoxic conditions because of a shift toward anaerobic metabolism $[33,34]$. By contrast, power output for tests with continuous or repeated high-intensity exercise longer than $45 \mathrm{~s}$, like the 3-min all-out critical power test and repeated sprints, is often reduced in acute hypoxia [20-22,24,32]. Therefore, we propose that performance tests assessing for anaerobic, high-intensity exercise performance in hypoxic conditions should last for more than $45 \mathrm{~s}$.

A number of studies have also examined the positive effects of supplementation with ergogenic aids such as sodium bicarbonate $\left(\mathrm{NaHCO}_{3}\right)$ or dietary nitrate as alkalotic buffers for attenuation of the impaired exercise performance under hypoxic conditions [32,35-39]. Ingestion of $\mathrm{NaHCO}_{3}$ increases the $\left[\mathrm{HCO}_{3}{ }^{-}\right]$concentration in extracellular fluids, which leads to an enhanced buffering of hydrogen $\left(\left[\mathrm{H}^{+}\right]\right)$ ions $[40,41]$. This $\left[\mathrm{HCO}_{3}{ }^{-}\right]$-induced increased buffering capacity seems to improve high-intensity exercise performance in normoxia [32,40,42] and hypoxia [32,35-37,43-45]. A few studies have examined the effect of $\mathrm{NaHCO}_{3}$ ingestion on anaerobic exercise performance at altitude. Although some studies found no effect of $\left[\mathrm{HCO}_{3}{ }^{-}\right]$supplementation on the power output of high-intensity exercise at simulated altitudes of $3000 \mathrm{~m}$ and $2500 \mathrm{~m}$ [46,47], a constant or improved anaerobic exercise performance at simulated altitude compared with anaerobic exercise performance under normoxic conditions was described for participants receiving alkalizing agent supplements prior to exercise [43-45]. In addition, positive effects of $\mathrm{NaHCO}_{3}$ ingestion under acute moderate normobaric hypoxic conditions during intermittent and repeated high-intensity exercise were reported [32,35-37]. In those studies, the authors concluded that $\mathrm{NaHCO}_{3}$ ingestion may offer an effective ergogenic strategy to alleviate hypoxia-induced declines in anaerobic exercise performance. 
Nevertheless, the effects of an alkalizing or acidizing dietary modification on anaerobic performance under hypoxic conditions has not been investigated to date. Nutrition has a strong impact on acid base balance [48-50], above all the urinary acid excretion, intestinal absorption rates of nutrients, and the dietary protein and mineral contents [51,52], which can be quantified via the potential renal acid load (PRAL) [49,53-55]. However remaining controversial [56,57], an improvement in anaerobic exercise performance after a low-PRAL (alkalizing) diet for tests with a duration of $60 \mathrm{~s}$ to $2 \mathrm{~min}[48,58,59]$, as well as an influence on blood and urinary $\mathrm{pH}$, and $\left[\mathrm{HCO}_{3}{ }^{-}\right]$, have often been described when following an alkalizing diet $[57,59,60]$.

Overall, these studies suggest that $\mathrm{NaHCO}_{3}$ ingestion and the associated $\left[\mathrm{HCO}_{3}{ }^{-}\right]$-induced enhanced buffering capacity may enhance high-intensity anaerobic exercise performance under acute normobaric hypoxic conditions [32,35-37,43-45]. Additionally, several studies propose that an alkalizing diet can change the blood buffer capacity, which influences high-intensity anaerobic exercise performance in a way similar to $\mathrm{NaHCO}_{3}$ ingestion $[48,58,59]$. However, there are no studies investigating the effects of a low-PRAL (alkalizing) or high-PRAL (acidizing) diet on anaerobic exercise performance after several hours of hypoxic exposure. Therefore, the aim of the present study was to investigate the influence of an alkalizing versus acidizing diet on a single bout of anaerobic exercise performance, maximum capillary blood lactate concentrations, blood gas parameters, heart rate (HR), rating of perceived exertion, and urinary $\mathrm{pH}\left(\mathrm{pH}_{\mathrm{u}}\right)$ in moderately trained young participants under normoxic conditions and after $12 \mathrm{~h}$ of exposure to hypoxia. We hypothesized that an alkalizing diet would enhance extracellular buffering capacity, and thus increase anaerobic exercise performance, under normoxic conditions, and mitigate potential hypoxia-induced declines in anaerobic exercise performance under hypoxic conditions.

\section{Materials and Methods}

\subsection{Participants}

Sixteen healthy, nonspecifically trained adult volunteers ( $n=8$ men, $n=8$ women) participated in the present study. One woman withdrew from the study because of a busy schedule. The results presented are for the remaining 15 participants. For men $(n=8)$, the mean $( \pm$ standard deviation) age was $24.6 \pm 4.6$ years, the mean height was $180.0 \pm 5.6 \mathrm{~cm}$, and the mean body mass was $72.1 \pm 5.5 \mathrm{~kg}$, while for women $(n=7)$ these values were $24.4 \pm 3.4$ years, $167.3 \pm 5.9 \mathrm{~cm}$, and $60.9 \pm 9.5 \mathrm{~kg}$, respectively. All participants underwent medical screening before entering the study. Participants had to be in good health with no pre-existing altitude illnesses, cardiac or pulmonary conditions, and no musculoskeletal injuries that could interfere with running activities. All participants lived close to sea level, were recreationally active (i.e., practicing various physical activities for $12 \mathrm{~h}$ per week), and were familiar with sprinting activities. Exclusion criteria included acute muscular injuries or restrictions, chronic medication intake, alcohol consumption, acute infections, and time spent above $2000 \mathrm{~m}$ in the four weeks prior to the investigation. In addition, individuals ingesting any nutritional supplements or following any specific diet in the two months prior to the initiation of the study were excluded. The study was approved by the ethical committee of the German Sport University Cologne in accordance with the Declaration of Helsinki. Participants gave their written informed consent after they had been informed of all experimental procedures and risks.

\subsection{Experimental Design}

The present investigation was conceptualized as a randomized, single-blind, counterbalanced crossover trial (Figure 1). Whereas investigators were blinded for treatment assignments, participants needed to be informed about necessary dietary modifications to obtain high or low PRAL values, but not about expected influences of the diets and associated hypotheses. After having ad libitum breakfast, all participants performed four anaerobic performance tests in a laboratory setting at intervals of one week under normoxic (NOR) conditions for the first two weeks and hypoxic (HYP) conditions 
in weeks 3 and 4 . To limit the effects of diurnal variation on the measured variables, the four anaerobic performance test trials were performed at approximately the same time each day. In a randomized order, an acidizing (ACID) or alkalizing (BASE) dietary intervention was followed, resulting in four groups (ABAB, ABBA, BAAB, BABA). This resulted in the four treatment conditions NOR ACID, NOR BASE, HYP ACID, and HYP BASE. Each dietary intervention was maintained for four days [56], followed by three washout-days with an unmodified diet before the next dietary intervention started in a crossover trial. Participants were requested to abstain from strenuous high-intensity exercise and alcohol for $24 \mathrm{~h}$ before each trial, and we requested compliance with these instructions before each anaerobic performance test trial.

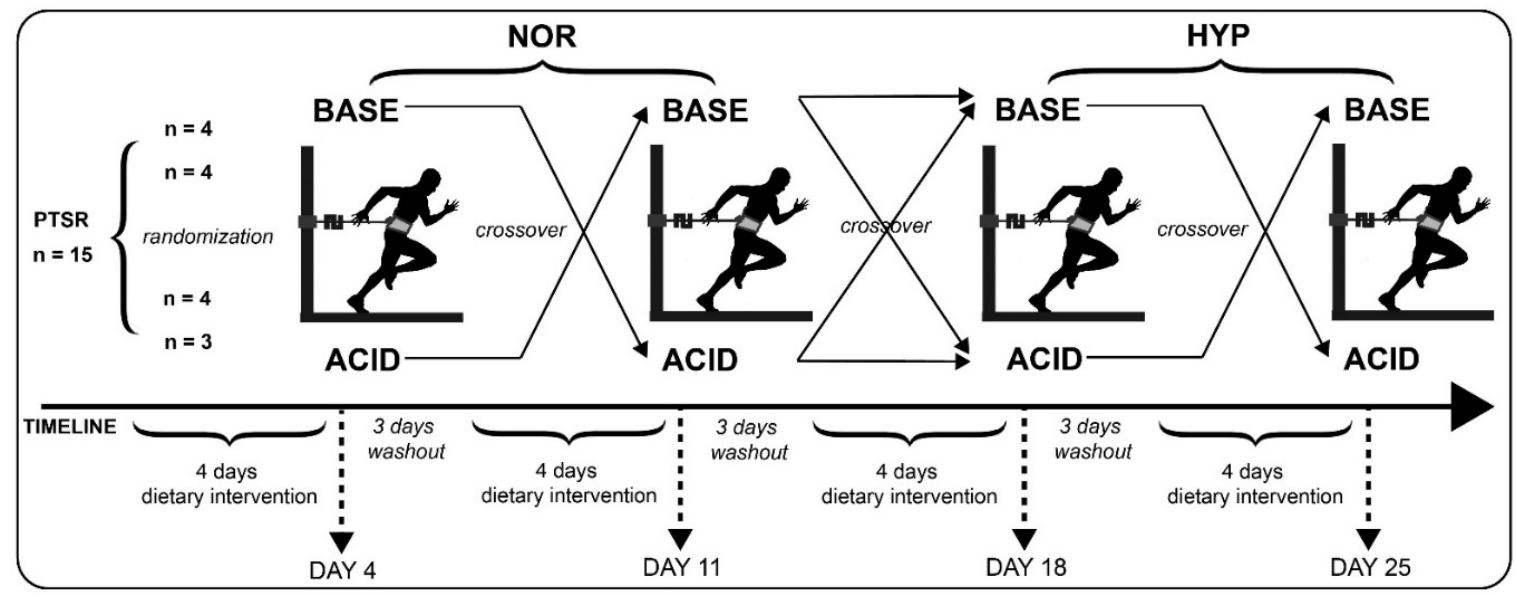

Figure 1. Experimental sequence. NOR = normoxia; HYP = hypoxia; PTSR = portable tethered sprint running test; $\mathrm{ACID}=$ acidizing diet; $\mathrm{BASE}=$ alkalizing diet.

\subsection{Dietary Interventions}

For the assessment of the daily PRAL values, as well as caloric and fluid intake, participants were asked to document all foods and beverages consumed during the dietary interventions using the Freiburger Nutrition Protocol (Freiburger Ernährungsprotokoll, Nutri-Science GmbH, Hausach, Germany). PRAL values represent a quantification of the effects of ingested nutrients on the acid-base status $[49,53]$. The PRAL model is based on the content of proteins, $\mathrm{Cl}^{-}, \mathrm{PO} 4^{3-}, \mathrm{SO}^{2-}, \mathrm{Na}^{+}, \mathrm{K}^{+}, \mathrm{Ca}^{2+}$, and $\mathrm{Mg}^{2+}$ [52] and was calculated as follows: PRAL $(\mathrm{mEq} / 100 \mathrm{~g})=0.49 \times$ protein $(\mathrm{g} / 100 \mathrm{~g})+0.037$ $\times$ phosphorus $(\mathrm{mg} / 100 \mathrm{~g})-0.021 \times$ potassium $(\mathrm{mg} / 100 \mathrm{~g})-0.026 \times$ magnesium $(\mathrm{mg} / 100 \mathrm{~g})-0.013$ $\times$ calcium (mg/100 g) [56]. In general, vegetables, fruits, and potatoes have the highest alkalizing potential (low-PRAL nutrients), while meat, cheese, cereal products, and eggs promote systemic acidity (high-PRAL nutrients) $[48,54,55]$. In addition, a German PRAL food list published by the Institute for Prevention and Nutrition, Ismaning, Germany, [52] and suggestions for recipes were given to the participants to meet the requirements of the alkalizing or acidizing diet. Participants were instructed to make food and amount choices ad libitum based on the respective PRAL values of foods. Following the common recommendations for PRAL-manipulating diets, participants were specifically instructed to eat mainly fruits and vegetables during the alkalizing, low-PRAL diet, combined with energy-dense foods such as starchy vegetables (e.g., potatoes and sweet potatoes), plant sources of fat (e.g., seeds and nuts, avocadoes), and dried fruits (e.g., figs, dates, and raisins). During the acidizing, high-PRAL diet, participants were instructed to eat mainly grains (e.g., oats, bread, pasta), hard cheese (e.g., parmesan), and meats. Nutrients with moderate PRAL values, such as white rice, yogurt, and legumes, were allowed for both dietary trials to ensure an adequate energy intake, especially for the alkalizing diet $[48,56]$. Based on the daily nutrition protocols, overall fluid intake ( $\sum$ fluid), caloric intake $\left(\sum \mathrm{CAL}\right)$, and overall PRAL sum value ( $\sum$ PRAL) were calculated for each participant for the four conditions of NOR ACID, NOR BASE, HYP ACID, and HYP BASE for statistical analyses. 


\subsection{Urinary $\mathrm{pH}$}

$\mathrm{pH}_{\mathrm{u}}$ was determined in spontaneous early morning urine samples (at least $5 \mathrm{~mL}$ of urine) using NeutralitßpH-indicator strips pH 5.0-10.0 (Merck, Darmstadt, Germany). $\mathrm{pH}_{\mathrm{u}}$ was measured on each day of the four-day dietary interventions, and served as a control marker to ensure that the dietary intervention had been implemented successfully [61]. The $\mathrm{pH}_{\mathrm{u}}$ of day 4 of the dietary intervention, when the portable tethered sprint running (PTSR) test was performed, was used for statistical analyses.

\subsection{High-Intensity Anaerobic Performance Test}

Anaerobic performance was measured using the PTSR test [62]. The PTSR test was chosen because it is simple, requires little space, and does not involve heavy and unwieldy equipment. The PTSR test is suitable for field studies investigating high-intensity exercise performance during altitude sojourns, as well as for the restricted space in hypoxic chambers, and thus allows direct comparability between studies in normobaric and hypobaric hypoxic conditions. For the test, participants ran in one place with a belt round their waist for force measurements. The belt was attached to an inextensible static rope combined in series with a load cell, and fixed to a pillar at $90^{\circ}$ to the subject's waist height. The belt was located at the iliac crest to assure that participants were not hampered to pull maximally against the tether. Before each PTSR test, the participants completed a pretest warm-up, which included 5 min of aerobic exercise and $5 \mathrm{~min}$ of coordination and dynamic stretching. 'Ready', 'Set', and 'Go' commands were provided, and the participant performed an all-out sprint for $60 \mathrm{~s}$. At ' $G o^{\prime}$ ', participants started to sprint at maximum effort and pulled with full force. Study investigators were all PTSR-experienced and provided strong verbal encouragement for the entire test duration to ensure that participants pulled the rope until voluntary exhaustion. Tethered running involves an often unfamiliar moving pattern. Participants who were not familiar with tethered running thus had to perform an additional habituation session prior to the first test trial to assure adequate test implementation of the PTSR test and related physiological responses. Force data were recorded and downloaded to an online PC using a sampling rate of $100 \mathrm{~Hz}$. Overall peak force (PF) and overall mean force (MF) over $60 \mathrm{~s}$ were recorded for subsequent analysis. Fatigue level during the PTSR test was assessed by calculating the fatigue index (FI), following the recommended calculations for Wingate tests [63]. HR was recorded as a control parameter throughout the tests using HR monitors (Polar T31; Polar Electro, Kempele, Finland). Thus, HR was measured before and after the PTSR tests. Maximal post-exercise HR after performance tests was used for further analyses. Blood lactate levels were measured in $20-\mu \mathrm{L}$ capillary blood samples collected from a hyperemized earlobe before and 2, 4, 6, 8, and 10 min after PTSR testing. Blood lactate measurements were carried out directly after each PTSR trial (Biosen S-Line; EKF-diagnostic GmbH, Magdeburg, Germany). The maximum post-exercise lactate concentration $\left(\mathrm{La}_{\max }\right)$ occurred mainly between 4 to $6 \mathrm{~min}$ after PTSR testing and was used for statistical analyses. Borg's rating of perceived exertion (RPE) was used to assess subjective perception of effort after each PTSR test [64]. Borg's RPE was explained to each participant by trained practitioners before the PTSR tests, and was used as a marker for the relationships between subjective measures of exertion and the objectively measured metabolic parameters of blood lactate and blood gas analysis.

\subsection{Blood Gas Analysis}

Capillary blood samples $(100 \mu \mathrm{L})$ were taken from a hyperemized earlobe before (PRE PTSR) and within 1 min after each PTSR trial (POST PTSR). Blood samples were immediately analyzed for blood gas parameters using a blood gas analyzer (ABL80 FLEX CO-OX; Radiometer, Willich, Germany). $\mathrm{PO}_{2}$, $\mathrm{PCO}_{2}$, blood $\mathrm{pH}\left(\mathrm{pH}_{\mathrm{b}}\right), \mathrm{S}_{\mathrm{a}} \mathrm{O}_{2}$, blood $\left[\mathrm{HCO}_{3}^{-}\right]$, and base excess (BE) were determined. For HYP trials, additional capillary blood samples were taken before entering the hypoxic chamber (PRE HYP) to assess them for influences on acid-base balance because of hypoxic conditions. 


\subsection{Anthropometric Characteristics}

Body weight was determined with a sliding weight mechanical scale (Seca 709; Seca, Hamburg, Germany). Height was measured (to the nearest $0.1 \mathrm{~cm}$ ) using the scale-integrated stadiometer.

\subsection{Hypoxic Conditions}

For HYP conditions in weeks 3 and 4 of the experimental period, all test subjects were exposed to a simulated altitude of $3000 \mathrm{~m}$. Altitude was simulated through nitrogen injection (VPSA S325 V16; van Amerongen, Tiel, The Netherlands) in a $65 \mathrm{~m}^{3}$ environmental chamber located at sea level. For simulation of an altitude of $3000 \mathrm{~m}$, inspired air consisted of $15.0 \% \mathrm{O}_{2}$, and the room temperature in the hypoxic chamber was kept at a constant level of $21-23{ }^{\circ} \mathrm{C}$ using air conditioning (42 WKR 61; Carrier, Neuss, Germany). For the conditions HYP ACID and HYP BASE, all test subjects were exposed to normobaric hypoxic conditions in two test sessions for $12 \mathrm{~h}$ overnight. Participants entered the hypoxic chamber in the evening between 8 p.m. and 9 p.m., and performed the PTSR test the next morning between 8 a.m. and 9 a.m. under hypoxic conditions after having ad libitum breakfast. Participants were asked to perform only quiet and sedentary activities without any further activity specifications during the 12 -h stay in the hypoxic chamber.

\subsection{Statistical Analysis}

Data are presented as mean \pm standard deviation. All departures from normal distribution were identified using the Shapiro-Wilk test. The effects of treatments on the parameters PF, MF, FI, Lamax, HR, RPE, $\mathrm{pH}_{\mathrm{u}}, \sum$ fluid, $\sum \mathrm{CAL}$, and $\sum$ PRAL over time (NOR ACID, NOR BASE, HYP ACID, and HYP BASE) were tested by one-way repeated-measures ANOVA, with sex (male and female) as a between-subject factor. The effects of treatments on the blood gas analysis parameters $P \mathrm{O}_{2}, P \mathrm{PO}_{2}, \mathrm{pH}_{\mathrm{b}}$, $\mathrm{S}_{\mathrm{a}} \mathrm{O}_{2},\left[\mathrm{HCO}_{3}{ }^{-}\right]$, and BE over time (NOR ACID PRE PTSR, NOR ACID POST PTSR, NOR BASE PRE PTSR, NOR BASE POST PTSR, PRE HYP ACID, HYP ACID PRE PTSR, HYP ACID POST PTSR, PRE HYP BASE, HYP BASE PRE PTSR, HYP BASE POST PTSR) were tested by one-way repeated-measures ANOVA, with sex (male and female) as a between-subject factor. Violations of the assumption of sphericity were corrected for by Greenhouse-Geisser adjustments. Two-tailed paired $t$-tests were utilized as post hoc tests to indicate significant differences. A Bonferroni procedure was used $\left(p^{*}\right)$ to retain an $\alpha=0.05$, and the significance level was set at $p \leq 0.05$ in all comparisons. Effect sizes were calculated using partial $\eta$ squared $\left(\eta p^{2}\right)$, and were interpreted as small (0.01), medium (0.06), and large (0.14). For post hoc analyses, Cohen's d $(d)$ was used to calculate effect sizes, with 0.2 considered to indicate a small effect, 0.5 a medium effect, and 0.8 a large effect [65].

We also performed stepwise multiple linear regression analyses to elucidate whether the variables $\sum$ PRAL, $\sum$ fluid, $\sum$ CAL, $\mathrm{pH}_{\mathrm{u}}, \mathrm{pH}_{\mathrm{b}}$ PRE PTSR, [ $\left.\mathrm{HCO}_{3}{ }^{-}\right]$PRE PTSR, and BE PRE PTSR were predictors of the PTSR-related performance measurements PF, MF, FI, Lamax, and HR. Furthermore, to determine which of the abovementioned variables may predict the PTSR-related measurement of RPE, we performed an ordinal logistic regression analysis.

Finally, we performed an a priori analysis to compute the required sample size for our study, based on a previous study [48], in which a low-PRAL, alkalizing diet resulted in a $21 \%$ improvement of anaerobic time to exhaustion $(2.56 \pm 0.36)$ compared with a high-PRAL, acidizing $\operatorname{diet}(2.11 \pm 0.31 \mathrm{~s})$. Using an $\alpha$-level of 0.05 , this indicated a sufficient sample size of eight participants to detect the expected changes with a power of at least 0.95 . The $\alpha$-level was set at $p \leq 0.05$, and all analyses were conducted using statistical software (SPSS v25; IBM Co., Armonk, NY, USA). The free software $\mathrm{G}^{*}$ Power was used to calculate the required sample sizes and effect sizes [66]. 


\section{Results}

\subsection{Dietary Intervention}

We found significant main effects for $\sum$ CAL $\left(p=0.014, \eta p^{2}=0.298\right)$ and $\sum$ PRAL $(p<0.001$, $\left.\eta p^{2}=0.888\right)$. There was no significant main effect for $\sum$ fluid $\left(p=0.893, \eta p^{2}=0.009\right)$. Post hoc analyses showed significantly lower values in $\sum$ CAL for NOR BASE $(5576.1 \pm 2125.4)$ compared with HYP $\operatorname{ACID}\left(7379.5 \pm 2066.6 \mathrm{kcal} ; p^{*}=0.038, d=0.86\right)$, and significantly higher values in $\sum$ PRAL for NOR ACID (142.6 $\pm 71.9 \mathrm{mEq} /$ day) compared with NOR BASE $\left(-222.3 \pm 118.6 \mathrm{mEq} /\right.$ day; $\left.p^{*}<0.001, d=3.53\right)$, HYP ACID $(175.6 \pm 38.3 \mathrm{mEq} /$ day $)$ compared with HYP BASE $\left(-255.0 \pm 103.0 \mathrm{mEq} /\right.$ day; $p^{*}<0.001$, $d=4.77)$, HYP ACID compared with NOR BASE $\left(p^{*}<0.001, d=3.80\right)$, and NOR ACID compared with HYP BASE $\left(p^{*}<0.001, d=4.35\right)$ (Figure 2A-C). The participants' sex had no influence on any of the dietary intervention parameters.
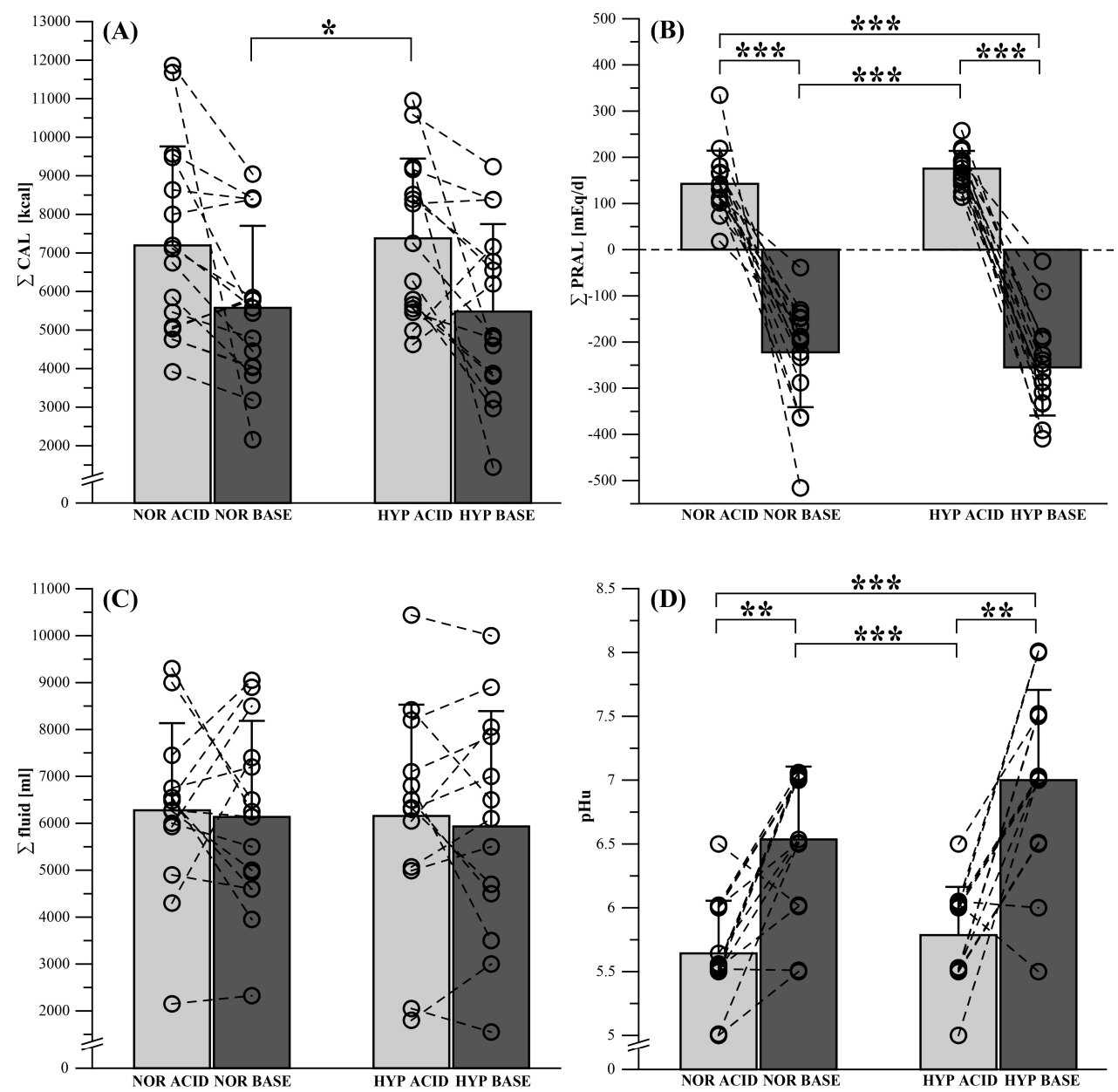

Figure 2. Changes in dietary intervention-related parameters after acidizing (ACID) and alkalinizing (BASE) diet under normoxic (NOR) and hypoxic (HYP) conditions for $(\mathbf{A})$ overall caloric intake $\left(\sum\right.$ CAL), (B) potential renal acid load sum value ( $\sum$ PRAL), and $(\mathbf{C})$ overall fluid intake ( $\sum$ fluid), as well as the associated physiological response of $(\mathbf{D})$ urinary $\mathrm{pH}\left(\mathrm{pH}_{\mathrm{u}}\right)$. Data points represent individual values $(\bigcirc)$. Bar charts are mean \pm standard deviation. ${ }^{*} p \leq 0.05,{ }^{* *} p \leq 0.01,{ }^{* * *} p \leq 0.001$. See Section 2. Materials and Methods for further details.

\subsection{Urinary $\mathrm{pH}$}

We found a main effect for $\mathrm{pH}_{\mathrm{u}}\left(p<0.001, \eta \mathrm{p}^{2}=0.655\right)$. Post hoc analyses showed significantly lower $\mathrm{pH}_{\mathrm{u}}$ values for NOR ACID (5.64 \pm 0.41$)$ compared with NOR BASE $\left(6.54 \pm 0.57 ; p^{*}=0.002\right.$, $d=1.75)$, HYP ACID $(5.79 \pm 0.38)$ compared with HYP BASE $\left(7.0 \pm 0.71{ }^{*}<0.001, d=1.98\right)$, HYP 
ACID compared with NOR BASE ( $p^{*}=0.007, d=1.49$ ), and NOR ACID compared with HYP BASE $\left(p^{*}<0.001, d=2.21\right)$ (Figure 2D). The participants' sex had no influence on $\mathrm{pH}_{\mathrm{u}}\left(p=0.376, \eta \mathrm{p}^{2}=0.078\right)$.

\subsection{High-Intensity Anaerobic Performance Test}

Results for all PTSR related parameters are shown in Figure 3. There were no significant main effects in PF $\left(p=0.158, \eta p^{2}=0.132\right), \operatorname{MF}\left(p=0.300, \eta p^{2}=0.088\right)$, and FI $\left(p=0.056, \eta p^{2}=0.174\right)$ (Figure 3A-C). However, there was a significant main effect for $\mathrm{La}_{\max }\left(p=0.011, \eta \mathrm{p}^{2}=0.246\right)$ (Figure 3D), with significantly lower $\mathrm{La}_{\max }$ values for male $(14.0 \pm 1.5 \mathrm{mmol} / \mathrm{L})$ compared with female participants $(10.6 \pm 0.9 \mathrm{mmol} / \mathrm{L} ; p<0.001)$. There were also no main effects in HR $\left(p=0.948, \eta p^{2}=0.009\right)$ and RPE $\left(p=0.780, \eta p^{2}=0.027\right)$ (Figure 3E,F). Additionally, the participants' sex showed no influence on PTSR-related parameters except for $\mathrm{La}_{\max }$.
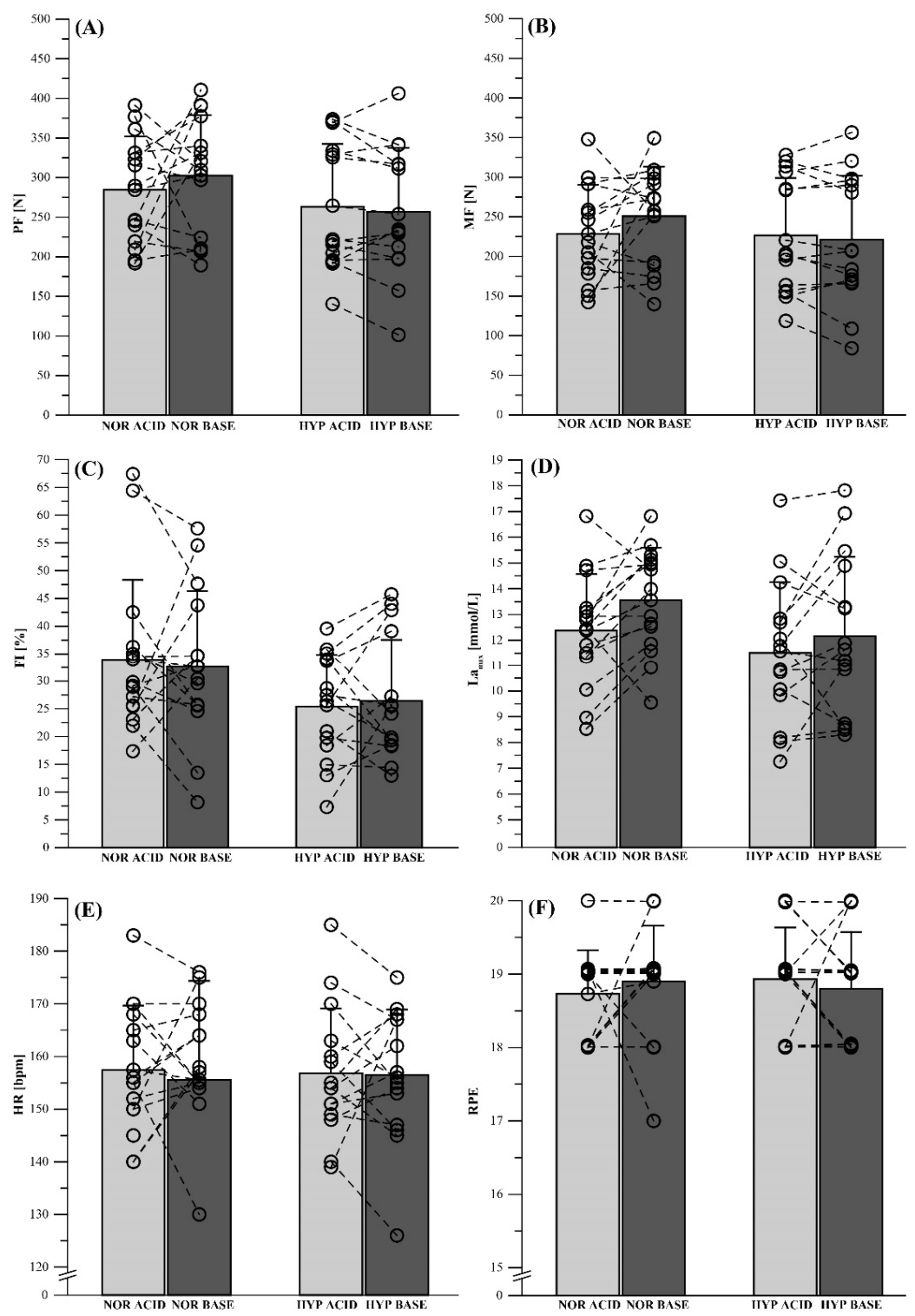

Figure 3. Performance measurements after acidizing (ACID) and alkalinizing (BASE) diet under normoxic (NOR) and hypoxic (HYP) conditions for (A) peak force (PF), (B) mean force (MF), and (C) fatigue index (FI), as well as the associated physiological response (D) maximum blood lactate $\left(\mathrm{La}_{\max }\right),(\mathrm{E})$ heart rate (HR), and (F) Borg's rating of perceived exertion (RPE). Data points represent individual values $(\bigcirc)$. Bar charts are mean \pm standard deviation. See Section 2. Materials and Methods for further details. 


\subsection{Blood Gas Analysis}

There was a significant main effect for $\mathrm{PO}_{2}\left(p<0.001, \eta p^{2}=0.761\right), \mathrm{PCO}_{2}\left(p<0.001, \eta p^{2}=0.450\right)$, $\mathrm{S}_{\mathrm{a}} \mathrm{O}_{2}\left(p<0.001, \eta \mathrm{p}^{2}=0.842\right), \mathrm{pH}_{\mathrm{b}}\left(p<0.001, \eta \mathrm{p}^{2}=0.941\right),\left[\mathrm{HCO}_{3}{ }^{-}\right]\left(p<0.001, \eta \mathrm{p}^{2}=0.914\right)$, and BE $\left(p<0.001, \eta p^{2}=0.931\right)$. Significant differences in post hoc tests are shown in Table 1 .

Table 1. Portable tethered sprint running test (PTSR)-related blood gas parameters after acidizing or alkalinizing diet under normoxic and hypoxic conditions.

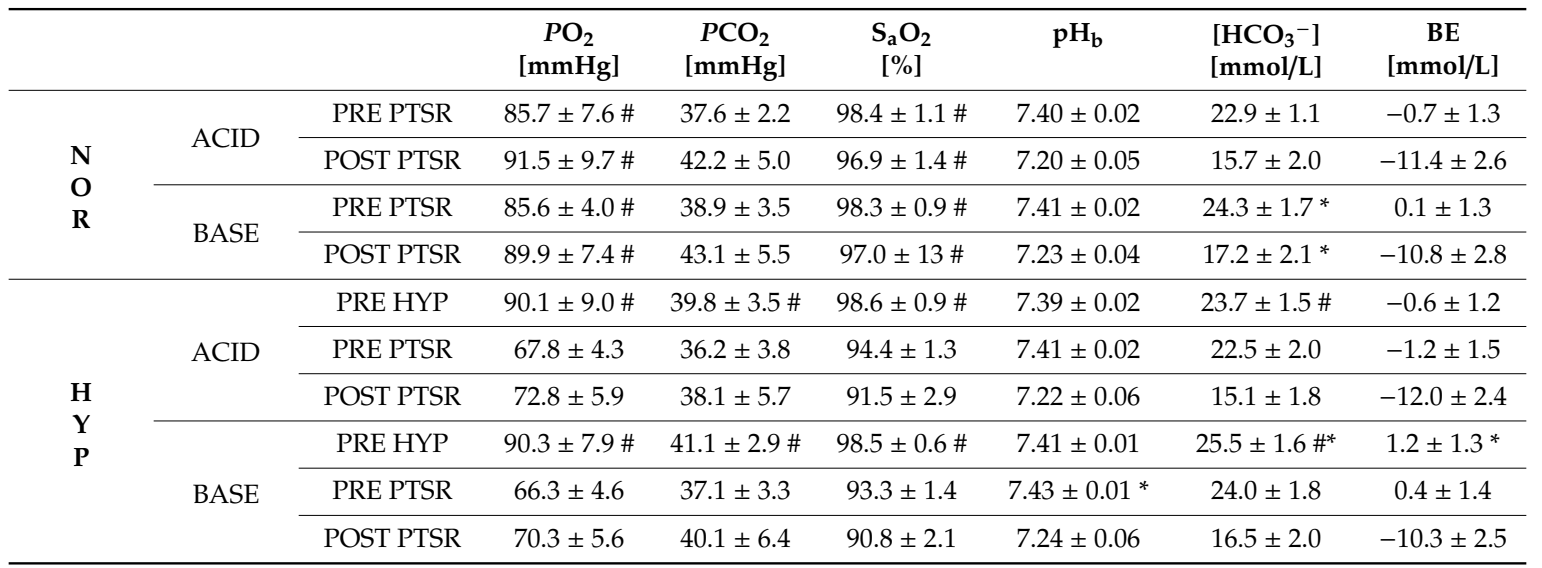

Note: Data are presented as mean \pm standard deviation. $P_{2}=$ oxygen partial pressure; $P_{C O}=$ carbon dioxide partial pressure; $\mathrm{S}_{\mathrm{a}} \mathrm{O}_{2}=$ oxygen saturation; $\mathrm{pH}_{\mathrm{b}}=$ blood $\mathrm{pH}$ value; $\left[\mathrm{HCO}_{3}{ }^{-}\right]=$blood bicarbonate concentration; $\mathrm{BE}=$ base excess; $\mathrm{ACID}=$ acidizing diet; $\mathrm{BASE}=$ alkalinizing diet; $\mathrm{NOR}=$ normoxia, $\mathrm{HYP}=$ hypoxia, $\mathrm{PRE}$ PTSR = pre-PTSR values; POST PTSR = post-PTSR values. For further details see Section 2. Materials and Methods ${ }^{*} p<0.05$ vs. ACID, \# $p<0.05$ vs. HYP. For $p$-values see Section 3. Results.

Additionally, the participants' sex showed a significant influence on $\mathrm{PCO}_{2}\left(p=0.045, \eta \mathrm{p}^{2}=0.177\right)$ and $\mathrm{pH}_{\mathrm{b}}\left(p=0.014, \eta \mathrm{p}^{2}=0.221\right)$. In post hoc analyses, male participants had significantly higher values for $\mathrm{PCO}_{2}$ compared with female participants in NOR BASE PRE PTSR (male: $41.4 \pm 2.9$, female: $36.2 \pm 1.5 \mathrm{mmHg} ; p^{*}=0.010, d=2.26$ ), HYP BASE PRE HYP (male: $42.9 \pm 2.5$, female: $39.0 \pm 1.8 \mathrm{mmHg}$; $p^{*}=0.040, d=1.85$ ), HYP BASE POST PTSR (male: $44.5 \pm 3.0$, female: $35.0 \pm 5.3 \mathrm{mmHg} ; p^{*}=0.020$, $d=2.19$ ), HYP ACID PRE HYP (male: $42.0 \pm 2.8$, female: $37.2 \pm 2.2 \mathrm{mmHg} ; p^{*}=0.030, d=1.88$ ), and HYP ACID POST PTSR (male: $42.0 \pm 2.7$, female: $33.7 \pm 4.9 \mathrm{mmHg} ; p^{*}=0.010, d=2.12$ ). For $\mathrm{pH}_{\mathrm{b}}$, post hoc analyses showed significantly lower values in HYP BASE POST PTSR for male (7.20 \pm 0.03$)$ compared with female participants $\left(7.28 \pm 0.05 ; p^{*}=0.040, d=1.78\right)$. The participants' sex had no significant influence on $\mathrm{PO}_{2}\left(p=0.220, \eta p^{2}=0.094\right), \mathrm{S}_{\mathrm{a}} \mathrm{O}_{2}\left(p=0.131, \eta \mathrm{p}^{2}=0.108\right),\left[\mathrm{HCO}_{3}{ }^{-}\right](p=0.514$, $\left.\eta \mathrm{p}^{2}=0.059\right)$, or BE $\left(p=0.160, \eta p^{2}=0.117\right)$.

\subsection{Regression Analyses}

Multiple linear regression analyses revealed no relevant predictors for PF, MF, and FI incorporating the variables $\sum$ PRAL, $\sum$ fluid, $\sum$ CAL, $\mathrm{pH}_{\mathrm{u}}, \mathrm{pH}_{\mathrm{b}}$ PRE PTSR, [ $\left.\mathrm{HCO}_{3}{ }^{-}\right]$PRE PTSR, and BE PRE PTSR. However, $\left[\mathrm{HCO}_{3}{ }^{-}\right]$PRE PTSR was identified as a significant predictor for $\mathrm{La}_{\max }$ and $\mathrm{pH}_{\mathrm{b}}$, while PRE PTSR was identified as a significant predictor for HR, whereas the variables $\sum$ PRAL, $\sum$ fluid, $\sum$ CAL, $\mathrm{pH}_{\mathrm{u}}$, and BE PRE PTSR did not significantly predict $\mathrm{La}_{\max }$ and HR. The results of the multiple linear regression analyses on $\mathrm{La}_{\max }$ and $\mathrm{HR}$ are shown in Table 2. Relationships between $\mathrm{La}_{\max }$ and $\left[\mathrm{HCO}_{3}{ }^{-}\right]$ PRE PTSR, as well as HR and pHb PRE PTSR, are shown in Figure 4. Ordinal logistic regression analysis revealed no significant result in the main model fitting for $\operatorname{RPE}\left(\chi^{2}=08.495, p=0.273\right)$. 


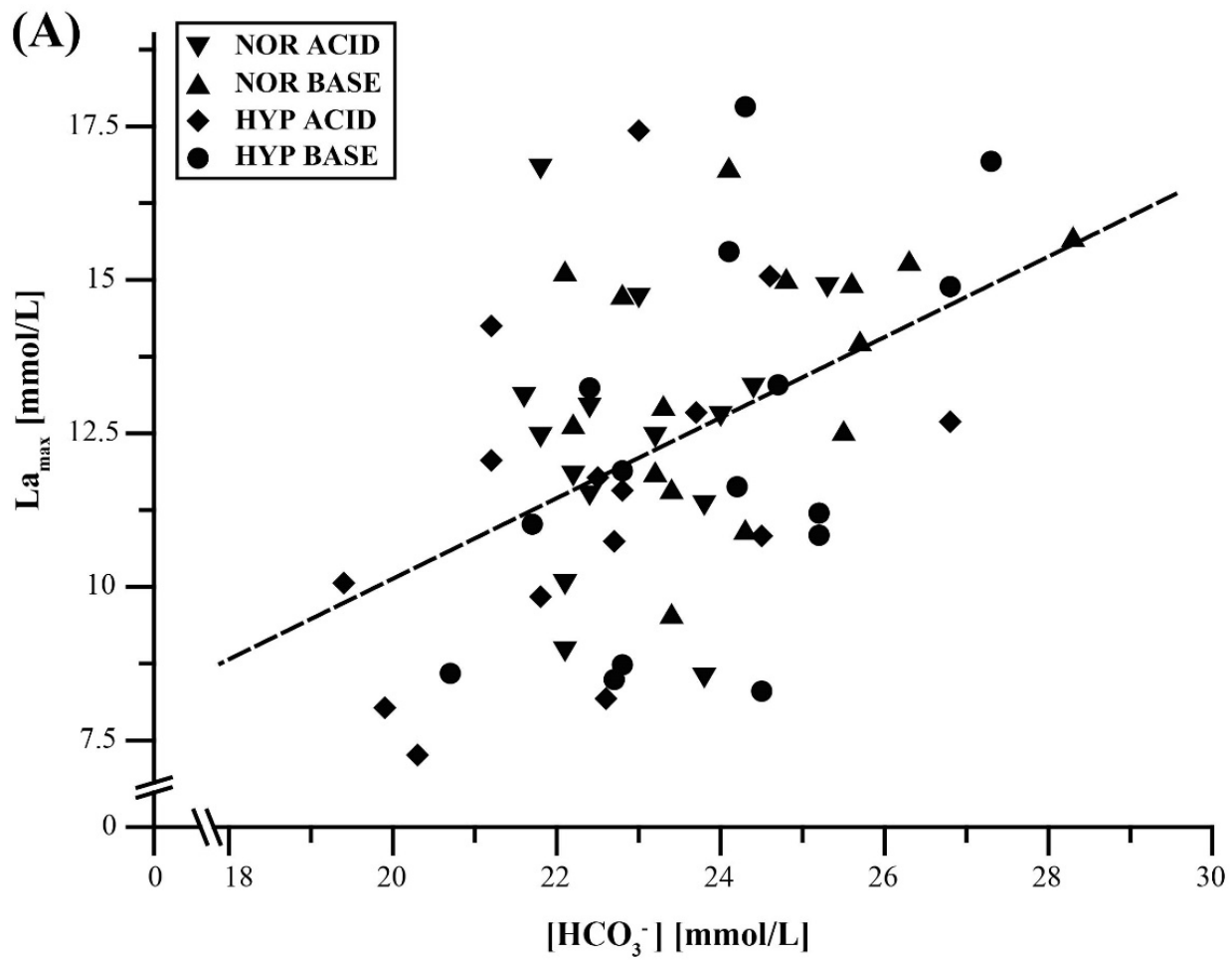

(B)

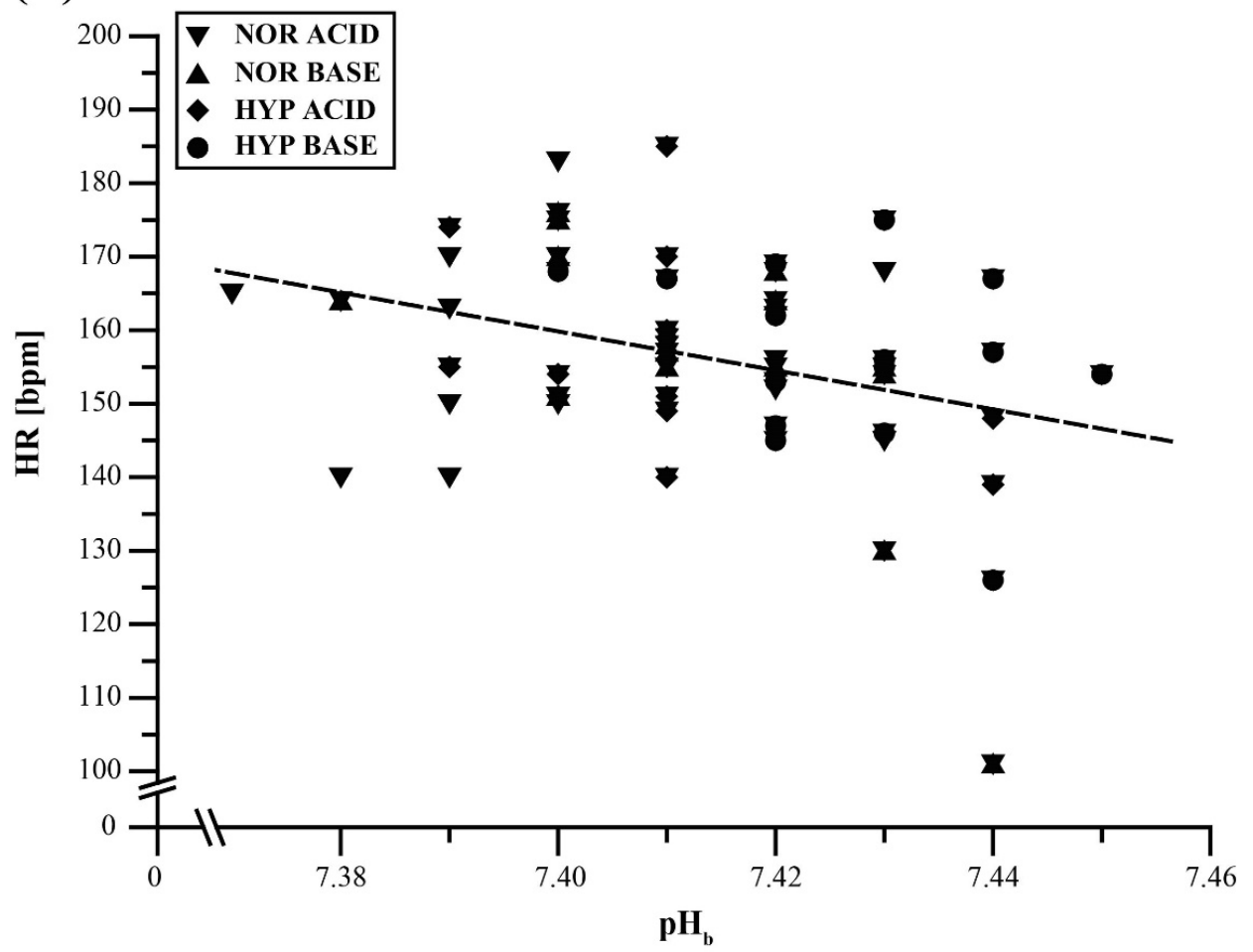

Figure 4. Relationships between PTSR-related (A) maximum post-exercise lactate concentration (Lamax) and (B) heart rate (HR) and the blood gas measurements before PTSR tests of blood $\mathrm{pH}\left(\mathrm{pH}_{\mathrm{b}}\right.$ PRE PTSR) and blood bicarbonate ([HCO $\left.{ }^{-}\right]$PRE PTSR). Data points represent individual values for the four treatment conditions NOR ACID $(n=15)$, NOR BASE $(n=15), \operatorname{HYP} \operatorname{ACID}(n=15)$, and HYP BASE $(n=15)$. NOR = normoxia, HYP = hypoxia, ACID $=$ acidizing diet, and BASE $=$ alkalinizing diet. See Section 2. Materials and Methods for further details. 
Table 2. Linear multiple regression analysis on portable tethered sprint running test (PTSR)-related maximum post-exercise lactate concentration $\left(\mathrm{La}_{\max }\right)$ and heart rate $(\mathrm{HR})$.

\begin{tabular}{|c|c|c|c|c|c|c|c|c|}
\hline & Predictor Variable & $R^{2}$ & Corrected $\mathbf{R}^{2}$ & F & $\mathbf{p}$ & Standardized $\beta$ & $\mathbf{T}$ & $\mathrm{p}$ \\
\hline \multirow{8}{*}{$\mathrm{La}_{\max }$} & Model & 0.200 & 0.184 & 12.746 & $0.001 *$ & & & \\
\hline & $\sum$ PRAL & & & & & 0.073 & 0.539 & 0.592 \\
\hline & $\sum$ Fluid & & & & & 0.030 & 0.241 & 0.811 \\
\hline & $\sum \mathrm{CAL}$ & & & & & 0.145 & 1.163 & 0.250 \\
\hline & $\mathrm{pH}_{\mathrm{u}}$ & & & & & -0.212 & -1.689 & 0.097 \\
\hline & $\mathrm{pH}_{\mathrm{b}}$ PRE PTSR & & & & & -0.224 & -1.823 & 0.074 \\
\hline & [HCO3-] PRE PTSR & & & & & 0.447 & 3.570 & $0.001 *$ \\
\hline & BE PRE PTSR & & & & & -0.304 & -1.021 & 0.312 \\
\hline \multirow{8}{*}{ HR } & Model & 0.091 & 0.073 & 5.084 & $0.028 *$ & & & \\
\hline & $\sum$ PRAL & & & & & -0.176 & -1.255 & 0.215 \\
\hline & $\sum$ fluid & & & & & 0.065 & 0.480 & 0.633 \\
\hline & $\bar{\Sigma} \mathrm{CAL}$ & & & & & 0.168 & 1.265 & 0.212 \\
\hline & $\mathrm{pH}_{\mathrm{u}}$ & & & & & 0.089 & 0.603 & 0.550 \\
\hline & $p H_{b}$ PRE PTSR & & & & & -0.301 & -2.255 & $0.028 *$ \\
\hline & {$\left[\mathrm{HCO}_{3}{ }^{-}\right]$PRE PTSR } & & & & & 0.172 & 1.294 & 0.202 \\
\hline & BE PRE PTSR & & & & & 0.183 & 1.367 & 0.178 \\
\hline
\end{tabular}

Note: Linear multiple regression on $\mathrm{La}_{\max }$ and $\mathrm{HR}$ in response to potential renal acid load sum value $\left(\sum \mathrm{PRAL}\right)$, overall fluid intake ( $\sum$ fluid), overall caloric intake $\left(\sum \mathrm{CAL}\right)$, urinary $\mathrm{pH}\left(\mathrm{pH}_{\mathrm{u}}\right)$, baseline blood $\mathrm{pH}$ value $\left(\mathrm{pH}_{\mathrm{b}}\right.$ PRE PTSR), baseline blood $\left[\mathrm{HCO}_{3}{ }^{-}\right]$([HCO $\left.{ }^{-}\right]$PRE PTSR), and baseline BE (BE PRE PTSR); $(n=60) .{ }^{*} p \leq 0.05$.

\section{Discussion}

The central aim of this study was to determine the effect of an alkalizing versus acidizing diet on a single bout of high-intensity exercise performance represented by PTSR test performance outputs, maximum capillary blood lactate concentrations, blood gas parameters, HR, rating of perceived exertion, and urinary $\mathrm{pH}$ in moderately trained young participants under normoxic conditions and after $12 \mathrm{~h}$ of exposure to a simulated altitude of $3000 \mathrm{~m}$ above sea level. As such, the main finding of the study was that alkalizing or acidizing diets had no significant influence on PTSR-related performance outputs and associated physiological responses, regardless of a high impact of the dietary interventions on acid-base balance.

We assumed an adequate implementation of the dietary intervention because overall PRAL values, which represent the acid- or base-forming potential of consumed nutrients, differed significantly between the ACID and BASE conditions. Positive PRAL values reflect an excess of acid-forming, acidizing potential, whereas negative values reflect an excess of base-forming, alkalizing potential $[49,53]$, and we found significantly higher PRAL values for ACID conditions compared with BASE conditions in the present study. Thus, we conclude that our specific instructions for the modification of the participants' habitual diets were understandable and feasible for the study participants, and that the dietary interventions were able to be included in a daily routine. The conclusion of a successful dietary modification is supported by significantly increased $\mathrm{pH}_{\mathrm{u}}$ values during the BASE trials, in contrast with the ACID trials. In a recent study, $\mathrm{pH}_{\mathrm{u}}$ was used as a surrogate marker for a successfully-conducted dietary intervention, and in general, a $\mathrm{pH}_{\mathrm{u}}$ of $\geq 7.0$ was proposed for successful alkalizing diets and $\leq 6.0$ for acidizing diets [48,61]. Thus, we assume that the significant increase in $\mathrm{pH}_{\mathrm{u}}$ values in the present study represents a profound impact on acid-base balance because of the alkalizing or acidizing diets. In addition, the impact of the dietary interventions on acid-base balance can be estimated by blood gas analysis parameters, and an increase in $\left[\mathrm{HCO}_{3}{ }^{-}\right]$ concentration and elevated $\mathrm{pH}_{\mathrm{b}}$ are both found after acid-base manipulation with ergogenic aids such as $\mathrm{NaHCO}_{3}[40,41]$.

A few recent studies have suggested that alkalizing diets are unable to produce the same severe effect on acid-base balance and blood buffering capacity compared with alkalizing ergogenic aids [55,67]. However, the present study showed significantly increased $\mathrm{pH}_{\mathrm{b}},\left[\mathrm{HCO}_{3}{ }^{-}\right]$, and $\mathrm{BE}$ values for the BASE condition compared with the ACID conditions, indicating a higher alkalotic state prior to PTSR exercise testing for the BASE trials. It was suggested that metabolic manipulation of the acid-base 
balance by $\mathrm{NaHCO}_{3}$ ingestion enhances anaerobic exercise performance by increasing the availability of $\left[\mathrm{HCO}_{3}{ }^{-}\right]$, thereby strengthening the physiochemical processes of buffering capacity (e.g., stimulation of the lactate/[ $\left.\mathrm{H}^{+}\right]$cotransporter) and leading to increased removal of $\left[\mathrm{H}^{+}\right]$during exercise $[32,40,42]$. The suggested mechanism underlying the increased $\left[\mathrm{H}^{+}\right]$efflux from the intracellular to extracellular compartments involves increased removal of $\left[\mathrm{H}^{+}\right]$from the extracellular buffering systems $[40,41]$, as well as improved protection of intramuscular $\mathrm{pH}$ and increased anaerobic energy provision and glycogen utilization $[66,68]$. Therefore, this leads to the assumption that the higher alkalotic state prior to exercise for the alkalizing diet trials within the present study would result in higher performance outputs in the PTSR trial.

However, despite an apparent influence of the dietary intervention on acid-base balance parameters and blood buffer capacity, the alkalizing or acidizing diets had no significant effect on PTSR-related performance parameters (PF, MF, and FI), or on the associated physiologic responses of $\mathrm{La}_{\max }$ and HR. It was previously reported that pre-alkalization prior to exercise had an ergogenic effect for anaerobic exercise performance under normoxic [32,40,42] and hypoxic conditions [32,35-37,43-45]. However, whereas $\mathrm{NaHCO}_{3}$ ingestion is a well-established method for an enhancement of anaerobic performance, the influence of an alkalizing diet on anaerobic exercise performance is still controversially discussed [67] and some investigations reported for less pronounced systemic alkalinity, blood buffer capacity, and an unaffected anaerobic exercise performance after an alkalizing diet [56-58]. The present study contributes to this negative assumption as we found no differences in any of the PTSR-related parameters for the ACID or BASE trials under either normoxic or hypoxic conditions. In addition, we assumed that the hypoxia-induced declines in high-intensity, anaerobic exercise performance would appear under normobaric hypoxic conditions, because a significant impairment of anaerobic exercise performance was previously reported [20-25], and as a reduced $\left[\mathrm{HCO}_{3}{ }^{-}\right]$concentration and accompanying acidification of extracellular fluids as a consequence of the renal compensation to hypoxia-induced respiratory alkalosis was reported to negatively affect exercise performance at altitude, particularly above the lactate threshold [10,16-19]. In the present study, we observed significantly reduced $\mathrm{PO}_{2}, \mathrm{PCO}_{2}, \mathrm{~S}_{\mathrm{a}} \mathrm{O}_{2}$, and $\left[\mathrm{HCO}_{3}{ }^{-}\right]$values after $12 \mathrm{~h}$ of exposure to a simulated altitude of $3000 \mathrm{~m}$, indicating a hypoxia-induced respiratory alkalosis. However, a respiratory alkalosis is typically associated with elevated $\mathrm{pH}_{\mathrm{b}}$ values, which we did not observe. This lack of effect on $\mathrm{pH}_{\mathrm{b}}$ may be attributed to an ongoing renal compensation of the respiratory alkalosis with subsequent $\left[\mathrm{HCO}_{3}{ }^{-}\right]$loss and restoration of $\mathrm{pH}_{\mathrm{b}}$ to normal. However, this assumption should be treated with caution because we did not perform hourly acid-base analysis under hypoxic conditions, and our data do not allow for direct deduction of a $\left[\mathrm{HCO}_{3}{ }^{-}\right]$loss and $\mathrm{pH}_{\mathrm{b}}$ stabilization based on the lack of a significant increase in $\mathrm{pH}_{\mathrm{b}}$. Nevertheless, the apparent discrepancies in anaerobic performance outputs and expected diet- or hypoxia-induced changes may be attributable to several factors, as detailed below.

First, we observed a reduced caloric intake for the BASE trials compared with the ACID trials, despite food recommendations for an adequate energy intake during the BASE trial. A caloric deficit during consuming alkalizing diets was previously reported [59], and alkalizing dietary recommendations are presumed for caloric deficits [69]. When consuming alkalizing diets, increasing the consumption of fruits and vegetables, and minimizing consumption of protein (e.g., meats, cheese) and carbohydrate sources (e.g., grains such as bread or pasta) [54], are often suggested to achieve low PRAL values. It is well established that an alkalizing diet makes it difficult to maintain the high caloric intake necessary to meet the high energy demands, and the requirement for dietary protein and carbohydrate sources, reported for sport disciplines with a high anaerobic contribution of energy production $[53,54,56]$. In particular, an influence of carbohydrate intake on exercise performance with high anaerobic demands was previously reported $[70,71]$. We provided ad libitum breakfast prior to the PTSR tests but omitted to standardize caloric and carbohydrate intake during breakfast. This may have resulted in individual differences in glucose and glycogen availability and an influence on performance data, and should therefore be considered as a limitation of this investigation. Furthermore, within the present study the caloric deficit and associated reduction in carbohydrate intake under BASE 
conditions may have mitigated the ergogenic effects of the pre-alkalization. Indeed, consumption of carbohydrate-rich vegetables and fruits, such as fresh and dried fruits, fruit juices, and potatoes, was highly advised to participants when specific instructions for the nutritional modification were explained prior to the test trials [48]. However, in that study, despite a high commitment for implementation of dietary instructions, participants were not able to maintain caloric intake during the BASE trials. Thus, future studies should focus on completion of food diaries, as well as a rigorous control of food intake using daily contact with a dietician to provide specific and individual food suggestions. Additionally, the use of mineral waters rich in $\left[\mathrm{HCO}_{3}{ }^{-}\right]$should be encouraged to simplify achieving an alkalizing diet while maintaining the high-energy diet required for anaerobic exercise performance [53,72,73].

Second, we examined a single bout of anaerobic exercise performance using the PTSR test. The PTSR test was selected because it is simple to setup, requires minimal space, and does not involve heavy and unwieldy equipment. These aspects are important when planning for investigations in altitude field settings. Field investigations assessing exercise performance during mountaineering tours and high-altitude expeditions may require the test equipment to be carried, and the anaerobic testing to be performed in restricted spaces (e.g., a mountain hut). Thus, the PTSR test is one of only a few tests feasible for the investigation of anaerobic exercise performance in altitude field conditions [62]. Other test procedures for the assessment of anaerobic exercise performance in the laboratory or field settings include evaluation of repeated sprint and intermittent sprint performance [74-76]. In this context, a recent review suggested that a single sprint of running or cycling activities in the laboratory environment of a hypoxic chamber is unaffected by acute exposure to normobaric hypoxia [77], while larger alterations in sprint outputs were found for repeated sprints or continuous high-intensity exercise lasting longer than $45 \mathrm{~s}$ [20,24,32,77]. Additionally, running performance is impaired for single bouts of performance in running distances of $800 \mathrm{~m}$ or longer when competing at altitudes above $1000 \mathrm{~m}$ [5]. This difference in anaerobic performance outputs may relate to the relatively low contributions of energy from aerobic metabolism required for efforts of short durations $(<45 \mathrm{~s})$, and thus the larger anaerobic contribution to the total energy requirement [78]. Aerobic energy availability for sprinting is reduced in oxygen deprived environments $[79,80]$. Therefore, whereas performance maintenance for single sprints of a short duration in hypoxic conditions is attributed to increased rates of anaerobic energy release that compensate for the reduced aerobic energy production, anaerobic exercise efforts of longer durations or multiple bouts are more affected by hypoxic conditions because of the higher aerobic energy contribution $[25,27,77]$. We assumed that a test duration of $60 \mathrm{~s}$ was sufficient for optimal assessment of continuous exhaustive anaerobic exercise performance as the aerobic/anaerobic energy contribution for a 400-m event usually lasting between 50-70 s was calculated as $41 \%$ or $59 \%$, respectively [81]. However, the lack of differences in performance outputs within the present study may among others relate to the applied exercise test protocol, and future investigations may further contribute to the still controversially discussed topic of impaired anaerobic exercise performance in hypoxia using different test protocols including assessments of all-out running for longer durations up to $3 \mathrm{~min}$ or repeated sprint performance.

The theory of strong ion difference (SID) may also explain the unexpected lack of an ergogenic effect of the alkalizing diet [82]. Our findings were based on the Henderson-Hasselbalch approach, which presumes that blood $\mathrm{pH}$ is determined by changes in $\left[\mathrm{H}^{+}\right]$and $\left[\mathrm{HCO}_{3}{ }^{-}\right]$. However, the contrasting SID theory incorporates intracellular and extracellular ions, and describes the difference between the concentrations of strong cations (sodium, potassium, calcium, and magnesium) and strong anions (lactate and chloride). The SID was also suggested to affect muscle performance by altering intracellular or extracellular $\mathrm{pH}$ because of an independent effect on blood $\mathrm{pH}$ [82]. The SID approach may therefore explain the increase in pre-PTSR $\left[\mathrm{HCO}_{3}{ }^{-}\right]$and $\mathrm{BE}$ for the BASE conditions with simultaneously persistent $\mathrm{pH}_{\mathrm{b}}$ in normoxia. Thus, acidizing dietary interventions may have had a positive impact on intracellular and extracellular ions, and following muscle performance, regardless of changes in $\left[\mathrm{H}^{+}\right]$and $\left[\mathrm{HCO}_{3}{ }^{-}\right]$. However, this conclusion should be interpreted with caution because no SID 
measurements were conducted in the present study. Thus, future studies are required to examine the influence of changes in the SID on anaerobic exercise performance under hypoxic conditions.

A low statistical test power is a common study limitation used to explain a lack of expected effects. Although an a priori analysis was performed prior to the present investigation, the number of 15 participants is still a small sample size and may result in small test power for statistical analyses. Thus, we reported our effect sizes, and found medium to large effect sizes for $\sum \mathrm{CAL}, \mathrm{PRAL}, \mathrm{pH}, \mathrm{PF}$, $\mathrm{MF}$, FI, $\mathrm{La}_{\max },{P \mathrm{O}_{2}}_{2}, P \mathrm{CO}_{2}, \mathrm{~S}_{\mathrm{a}} \mathrm{O}_{2}, \mathrm{pH}_{\mathrm{b}},\left[\mathrm{HCO}_{3}{ }^{-}\right]$, and $\mathrm{BE}$, ranging between $\eta \mathrm{p}^{2}=0.088$ and $\eta \mathrm{p}^{2}=0.941$. These data indicate sufficient testing power for analyzing the effect of an alkalizing or acidizing dietary intervention and normobaric hypoxic conditions on these parameters. Thus, we conclude that our sample size of 15 participants was sufficient to detect possible differences in the investigated dietary, PTSR-related, and BGA-related parameters, and to exclude a type 2 error within our interpretation.

\section{Conclusions}

We provide novel data on the effects of an alkalizing or acidizing dietary intervention on anaerobic exercise performance under normoxic or hypoxic conditions after $12 \mathrm{~h}$ of exposure to a simulated altitude of $3000 \mathrm{~m}$. Our principle finding was that dietary intervention significantly increased the blood buffer capacity, represented by pre-exercise $\left[\mathrm{HCO}_{3}{ }^{-}\right]$and BE values, but did not affect PTSR-related exercise performance outputs or associated physiologic parameters. A higher alkalotic state of the acid-base balance prior to exercise under hypoxic conditions is often associated with higher anaerobic performance outputs and higher maximum blood lactate values after high-intensity exercise in normoxic and hypoxic conditions. Explanations for the apparent lack of any ergogenic effect of pre-alkalization caused by an alkalizing diet include a reduced caloric intake for the BASE trials compared with the ACID trials, the duration of the 60-s portable tethered sprint test and the associated energy contributions, and possible changes in intracellular and extracellular ions other than $\left[\mathrm{H}^{+}\right]$ and $\left[\mathrm{HCO}_{3}^{-}\right]$.

Author Contributions: Conceptualization, M.L. and P.P.; methodology, M.L. and P.P.; validation, M.L., M.d.M. and P.P.; formal analysis, M.L.; investigation, M.L. and J.S.; resources, P.P.; data curation, M.L.; writing-original draft preparation, M.L.; writing-review and editing, M.L., M.d.M. and P.P.; visualization, M.L.; supervision, M.d.M. and P.P.; project administration, M.L. All authors have read and agreed to the published version of the manuscript.

Funding: The APC was funded by the DFG Open Access Publication Funds of the Ruhr-University Bochum.

Acknowledgments: We thank all subjects for participating in this study, our laboratory staff for contributions and support, and Edanz Group (https://en-author-services.edanzgroup.com/) for editing a draft of this manuscript.

Dataset: All datasets generated for this study are available from the figshare repository database (doi:10.6084/m9.figshare.11534547).

Conflicts of Interest: The authors declare no conflict of interest.

\section{References}

1. Losnegard, T.; Myklebust, H.; Hallen, J. Anaerobic capacity as a determinant of performance in sprint skiing. Med. Sci. Sports Exerc. 2012, 44, 673-681. [CrossRef] [PubMed]

2. Hydren, J.R.; Kraemer, W.J.; Volek, J.S.; Dunn-Lewis, C.; Comstock, B.A.; Szivak, T.K.; Hooper, D.R.; Denegar, C.R.; Maresh, C.M. Performance changes during a weeklong high-altitude alpine ski-racing training camp in lowlander young athletes. J. Strength Cond. Res. 2013, 27, 924-937. [CrossRef] [PubMed]

3. Wirnitzer, K.C.; Kornexl, E. Exercise intensity during an 8-day mountain bike marathon race. Eur. J. Appl. Physiol. 2008, 104, 999-1005. [CrossRef] [PubMed]

4. McSharry, P.E. Effect of altitude on physiological performance: A statistical analysis using results of international football games. BMJ 2007, 335, 1278-1281. [CrossRef]

5. Hamlin, M.J.; Hopkins, W.G.; Hollings, S.C. Effects of altitude on performance of elite track-and-field athletes. Int. J. Sports Physiol. Perform. 2015, 10, 881-887. [CrossRef]

6. Watts, P.B. Physiology of difficult rock climbing. Eur. J. Appl. Physiol. 2004, 91, 361-372. [CrossRef] 
7. Bertuzzi, R.C.; Franchini, E.; Kokubun, E.; Kiss, M.A. Energy system contributions in indoor rock climbing. Eur. J. Appl. Physiol. 2007, 101, 293-300. [CrossRef]

8. Baertsch, P. Innere Medizin: Hoehenanpassung. Dtsch. Z. Sportmed. 2000, 51, 139-140.

9. Mazzeo, R.S. Physiological responses to exercise at altitude: An update. Sports Med. 2008, 38, 1-8. [CrossRef]

10. West, J. High Altitude Medicine and Physiology, 5th ed.; CRC Press: Hoboken, NJ, USA, 2012; ISBN 9781444154320.

11. Swenson, E.R. Hypoxia and its acid-base consequences: From mountains to malignancy. Adv. Exp. Med. Biol. 2016, 903, 301-323. [CrossRef]

12. Zubieta-Calleja, G.; Zubieta-Castillo, G.; Zubieta-Calleja, L.; Ardaya-Zubieta, G.; Paulev, P.-E. Do over 200 million healthy altitude residents really suffer from chronic acid-base disorders? Indian J. Clin. Biochem. 2011, 26, 62-65. [CrossRef] [PubMed]

13. Ramirez-Sandoval, J.C.; Castilla-Peon, M.F.; Gotes-Palazuelos, J.; Vazquez-Garcia, J.C.; Wagner, M.P.; Merelo-Arias, C.A.; Vega-Vega, O.; Rincon-Pedrero, R.; Correa-Rotter, R. Bicarbonate values for healthy residents living in cities above 1500 meters of altitude: A theoretical model and systematic review. High Alt. Med. Biol. 2016, 17, 85-92. [CrossRef] [PubMed]

14. Duffin, J. Role of acid-base balance in the chemoreflex control of breathing. J. Appl. Physiol. Respir. Environ. Exerc. Physiol. 2005, 99, 2255-2265. [CrossRef] [PubMed]

15. Osnes, J.B.; Hermansen, L. Acid-base balance after maximal exercise of short duration. J. Appl. Physiol. 1972, 32, 59-63. [CrossRef]

16. Cerretelli, P.; Samaja, M. Acid-base balance at exercise in normoxia and in chronic hypoxia. Revisiting the "lactate paradox". Eur. J. Appl. Physiol. 2003, 90, 431-448. [CrossRef]

17. Coudert, J. Anaerobic performance at altitude. Int. J. Sports Med. 1992, 13 (Suppl. 1), 5. [CrossRef]

18. Yoshida, T.; Udo, M.; Chida, M.; Makiguchi, K.; Ichioka, M.; Muraoka, I. Arterial blood gases, acid-base balance, and lactate and gas exchange variables during hypoxic exercise. Int. J. Sports Med. 1989, 10, $279-285$. [CrossRef]

19. Rusko, H.K.; Tikkanen, H.O.; Peltonen, J.E. Altitude and endurance training. J. Sports Sci. 2004, $22,928$. [CrossRef]

20. Sweeting, A.J.; Billaut, F.; Varley, M.C.; Rodriguez, R.F.; Hopkins, W.G.; Aughey, R.J. Variations in hypoxia impairs muscle oxygenation and performance during simulated team-sport running. Front. Physiol. 2017, 8, 80. [CrossRef] [PubMed]

21. Gatterer, H.; Menz, V.; Untersteiner, C.; Klarod, K.; Burtscher, M. Physiological factors associated with declining repeated sprint performance in hypoxia. J. Strength Cond. Res. 2017, 33, 211-216. [CrossRef]

22. Dekerle, J.; Mucci, P.; Carter, H. Influence of moderate hypoxia on tolerance to high-intensity exercise. Eur. J. Appl. Physiol. 2012, 112, 327-335. [CrossRef] [PubMed]

23. McLellan, T.M.; Cheung, S.S.; Meunier, M.R. The effect of normocapnic hypoxia and the duration of exposure to hypoxia on supramaximal exercise performance. Eur. J. Appl. Physiol. Occup. Physiol. 1993, 66, 409-414. [CrossRef] [PubMed]

24. Simpson, L.P.; Jones, A.M.; Skiba, P.F.; Vanhatalo, A.; Wilkerson, D. Influence of hypoxia on the power-duration relationship during high-intensity exercise. Int. J. Sports Med. 2015, 36, 113-119. [CrossRef] [PubMed]

25. Morales-Alamo, D.; Ponce-Gonzalez, J.G.; Guadalupe-Grau, A.; Rodriguez-Garcia, L.; Santana, A.; Cusso, M.R.; Guerrero, M.; Guerra, B.; Dorado, C.; Calbet, J.A.L. Increased oxidative stress and anaerobic energy release, but blunted Thr172-AMPKalpha phosphorylation, in response to sprint exercise in severe acute hypoxia in humans. J. Appl. Physiol. (1985) 2012, 113, 917-928. [CrossRef]

26. Burtscher, M.; Faulhaber, M.; Flatz, M.; Likar, R.; Nachbauer, W. Effects of short-term acclimatization to altitude $(3200 \mathrm{~m})$ on aerobic and anaerobic exercise performance. Int. J. Sports Med. 2006, 27, 629-635. [CrossRef]

27. McLellan, T.M.; Kavanagh, M.F.; Jacobs, I. The effect of hypoxia on performance during $30 \mathrm{~s}$ or $45 \mathrm{~s}$ of supramaximal exercise. Eur. J. Appl. Physiol. Occup. Physiol. 1990, 60, 155-161. [CrossRef]

28. Ogura, Y.; Katamoto, S.; Uchimaru, J.; Takahashi, K.; Naito, H. Effects of low and high levels of moderate hypoxia on anaerobic energy release during supramaximal cycle exercise. Eur. J. Appl. Physiol. 2006, 98, 41-47. [CrossRef] 
29. Oguri, K.; Fujimoto, H.; Sugimori, H.; Miyamoto, K.; Tachi, T.; Nagasaki, S.; Kato, Y.; Matsuoka, T. Pronounced muscle deoxygenation during supramaximal exercise under simulated hypoxia in sprint athletes. J. Sports Sci. Med. 2008, 7, 512-519.

30. Ge, R.-L.; Babb, T.G.; Sivieri, M.; Resaland, G.K.; Karlsen, T.; Stray-Gundersen, J.; Levine, B.D. Urine acid-base compensation at simulated moderate altitude. High Alt. Med. Biol. 2006, 7, 64-71. [CrossRef]

31. Luks, A.M. Physiology in Medicine: A physiologic approach to prevention and treatment of acute high-altitude illnesses. J. Appl. Physiol. Respir. Environ. Exerc. Physiol. 2015, 118, 509-519. [CrossRef]

32. Deb, S.K.; Gough, L.A.; Sparks, S.A.; McNaughton, L.R. Determinants of curvature constant (W') of the power duration relationship under normoxia and hypoxia: The effect of pre-exercise alkalosis. Eur. J. Appl. Physiol. 2017, 117, 901-912. [CrossRef] [PubMed]

33. Weyand, P.G.; Lee, C.S.; Martinez-Ruiz, R.; Bundle, M.W.; Bellizzi, M.J.; Wright, S. High-speed running performance is largely unaffected by hypoxic reductions in aerobic power. J. Appl. Physiol. Respir. Environ. Exerc. Physiol. 1999, 86, 2059-2064. [CrossRef] [PubMed]

34. Scott, B.R.; Goods, P.S.R.; Slattery, K.M. High-intensity exercise in hypoxia: Is increased reliance on anaerobic metabolism important? Front. Physiol. 2016, 7, 637. [CrossRef] [PubMed]

35. Deb, S.K.; Gough, L.A.; Sparks, S.A.; McNaughton, L.R. Sodium bicarbonate supplementation improves severe-intensity intermittent exercise under moderate acute hypoxic conditions. Eur. J. Appl. Physiol. 2018, 118, 607-615. [CrossRef] [PubMed]

36. Gough, L.A.; Deb, S.K.; Brown, D.; Sparks, S.A.; McNaughton, L.R. The effects of sodium bicarbonate ingestion on cycling performance and acid base balance recovery in acute normobaric hypoxia. J. Sports Sci. 2019, 37, 1464-1471. [CrossRef] [PubMed]

37. Gough, L.A.; Brown, D.; Deb, S.K.; Sparks, S.A.; McNaughton, L.R. The influence of alkalosis on repeated high-intensity exercise performance and acid-base balance recovery in acute moderate hypoxic conditions. Eur. J. Appl. Physiol. 2018, 118, 2489-2498. [CrossRef]

38. Shannon, O.M.; Duckworth, L.; Barlow, M.J.; Deighton, K.; Matu, J.; Williams, E.L.; Woods, D.; Xie, L.; Stephan, B.C.M.; Siervo, M.; et al. Effects of dietary nitrate supplementation on physiological responses, cognitive function, and exercise performance at moderate and very-high simulated altitude. Front. Physiol. 2017, 8, 401. [CrossRef]

39. Shannon, O.M.; McGawley, K.; Nybäck, L.; Duckworth, L.; Barlow, M.J.; Woods, D.; Siervo, M.; O’Hara, J.P. "Beet-ing" the mountain: A review of the physiological and performance effects of dietary nitrate supplementation at simulated and terrestrial altitude. Sports Med. 2017, 47, 2155-2169. [CrossRef]

40. McNaughton, L.R.; Gough, L.; Deb, S.; Bentley, D.; Sparks, S.A. Recent developments in the use of sodium bicarbonate as an ergogenic aid. Curr. Sports Med. Rep. 2016, 15, 233-244. [CrossRef]

41. Siegler, J.C.; Marshall, P.W.M.; Bishop, D.; Shaw, G.; Green, S. Mechanistic insights into the efficacy of sodium bicarbonate supplementation to improve athletic performance. Sports Med. Open 2016, 2, 41. [CrossRef]

42. Carr, A.J.; Slater, G.J.; Gore, C.J.; Dawson, B.; Burke, L.M. Effect of sodium bicarbonate on HCO3-, pH, and gastrointestinal symptoms. Int. J. Sport Nutr. Exerc. Metab. 2011, 21, 189-194. [CrossRef] [PubMed]

43. Feriche Fernandez-Castanys, B.; Delgado-Fernandez, M.; Alvarez Garcia, J. The effect of sodium citrate intake on anaerobic performance in normoxia and after sudden ascent to a moderate altitude. J. Sports Med. Phys. Fit. 2002, 42, 179-185.

44. Hausswirth, C.; Bigard, A.X.; Lepers, R.; Berthelot, M.; Guezennec, C.Y. Sodium citrate ingestion and muscle performance in acute hypobaric hypoxia. Eur. J. Appl. Physiol. Occup. Physiol. 1995, 71, 362-368. [CrossRef] [PubMed]

45. McLellan, T.; Jacobs, I.; Lewis, W. Acute altitude exposure and altered acid-base states. II. Effects on exercise performance and muscle and blood lactate. Eur. J. Appl. Physiol. Occup. Physiol. 1988, 57, 445-451. [CrossRef] [PubMed]

46. Flinn, S.; Herbert, K.; Graham, K.; Siegler, J.C. Differential effect of metabolic alkalosis and hypoxia on high-intensity cycling performance. J. Strength Cond. Res. 2014, 28, 2852-2858. [CrossRef] [PubMed]

47. Saunders, B.; Sale, C.; Harris, R.C.; Sunderland, C. Sodium bicarbonate and high-intensity-cycling capacity: Variability in responses. Int. J. Sports Physiol. Perform. 2014, 9, 627-632. [CrossRef]

48. Caciano, S.L.; Inman, C.L.; Gockel-Blessing, E.E.; Weiss, E.P. Effects of dietary acid load on exercise metabolism and anaerobic exercise performance. J. Sports Sci. Med. 2015, 14, 364-371. 
49. Remer, T. Influence of nutrition on acid-base balance-Metabolic aspects. Eur. J. Nutr. 2001, 40, $214-220$. [CrossRef]

50. Poupin, N.; Calvez, J.; Lassale, C.; Chesneau, C.; Tome, D. Impact of the diet on net endogenous acid production and acid-base balance. Clin. Nutr. 2012, 31, 313-321. [CrossRef]

51. Niekamp, K.; Zavorsky, G.S.; Fontana, L.; McDaniel, J.L.; Villareal, D.T.; Weiss, E.P. Systemic acid load from the diet affects maximal-exercise RER. Med. Sci. Sports Exerc. 2012, 44, 709-715. [CrossRef]

52. Remer, T.; Manz, F. Potential renal acid load of foods and its influence on urine pH. J. Am. Diet. Assoc. 1995, 95, 791-797. [CrossRef]

53. Deriemaeker, P.; Aerenhouts, D.; Hebbelinck, M.; Clarys, P. Nutrient based estimation of acid-base balance in vegetarians and non-vegetarians. Plant Foods Hum. Nutr. 2010, 65, 77-82. [CrossRef] [PubMed]

54. Aerenhouts, D.; Deriemaeker, P.; Hebbelinck, M.; Clarys, P. Dietary acid-base balance in adolescent sprint athletes: A follow-up study. Nutrients 2011, 3, 200-211. [CrossRef] [PubMed]

55. Arciero, P.J.; Miller, V.J.; Ward, E. Performance enhancing diets and the PRISE Protocol to optimize athletic performance. J. Nutr. Metab. 2015, 2015, 715859. [CrossRef]

56. Hietavala, E.-M.; Puurtinen, R.; Kainulainen, H.; Mero, A.A. Low-protein vegetarian diet does not have a short-term effect on blood acid-base status but raises oxygen consumption during submaximal cycling. J. Int. Soc. Sports Nutr. 2012, 9, 50. [CrossRef]

57. Ball, D.; Greenhaff, P.L.; Maughan, R.J. The acute reversal of a diet-induced metabolic acidosis does not restore endurance capacity during high-intensity exercise in man. Eur. J. Appl. Physiol. Occup. Physiol. 1996, 73, 105-112. [CrossRef]

58. Ball, D.; Maughan, R.J. The effect of sodium citrate ingestion on the metabolic response to intense exercise following diet manipulation in man. Exp. Physiol. 1997, 82, 1041-1056. [CrossRef]

59. Rios Enriquez, O.; Guerra-Hernandez, E.; Feriche Fernandez-Castanys, B. Efectos de la alcalosis metabolica inducida por la dieta en el rendimiento anaerobico de alta intensidad. Nutr. Hosp. 2010, 25, 768-773.

60. Hietavala, E.-M.; Stout, J.R.; Hulmi, J.J.; Suominen, H.; Pitkanen, H.; Puurtinen, R.; Selanne, H.; Kainulainen, H.; Mero, A.A. Effect of diet composition on acid-base balance in adolescents, young adults and elderly at rest and during exercise. Eur. J. Clin. Nutr. 2015, 69, 399-404. [CrossRef]

61. Welch, A.A.; Mulligan, A.; Bingham, S.A.; Khaw, K.-T. Urine $\mathrm{pH}$ is an indicator of dietary acid-base load, fruit and vegetables and meat intakes: Results from the European Prospective Investigation into Cancer and Nutrition (EPIC)-Norfolk population study. Br. J. Nutr. 2008, 99, 1335-1343. [CrossRef]

62. Limmer, M.; Berkholz, A.; de Marées, M.; Platen, P. Reliability and validity of a new portable tethered sprint running test as a measure of maximal anaerobic performance. J. Strength Cond. Res. 2019. [CrossRef] [PubMed]

63. Pendergast, D.R.; Meksawan, K.; Limprasertkul, A.; Fisher, N.M. Influence of exercise on nutritional requirements. Eur. J. Appl. Physiol. 2011, 111, 379-390. [CrossRef] [PubMed]

64. Borg, G.A. Psychophysical bases of perceived exertion. Med. Sci. Sports Exerc. 1982, 14, 377-381. [CrossRef]

65. Cohen, J. A power primer. Psychol. Bull. 1992, 112, 155-159. [CrossRef] [PubMed]

66. Faul, F.; Erdfelder, E.; Lang, A.-G.; Buchner, A. G*Power 3: A flexible statistical power analysis program for the social, behavioral, and biomedical sciences. Behav. Res. Methods 2007, 39, 175-191. [CrossRef] [PubMed]

67. Applegate, C.; Mueller, M.; Zuniga, K.E. Influence of dietary acid load on exercise performance. Int. J. Sport Nutr. Exerc. Metab. 2017, 1-21. [CrossRef] [PubMed]

68. Fitts, R.H. The role of acidosis in fatigue: Pro perspective. Med. Sci. Sports Exerc. 2016, 48, $2335-2338$. [CrossRef]

69. Limmer, M.; Eibl, A.D.; Platen, P. Enhanced 400-m sprint performance in moderately trained participants by a 4-day alkalizing diet: A counterbalanced, randomized controlled trial. J. Int. Soc. Sports Nutr. 2018, 15, 25. [CrossRef]

70. Couto, P.G.; Bertuzzi, R.; de Souza, C.C.; Lima, H.M.; Kiss, M.A.; de-Oliveira, F.R.; Lima-Silva, A.E. High carbohydrate diet induces faster final sprint and overall 10,000-m times of young runners. Pediatr. Exerc. Sci. 2015, 27, 355-363. [CrossRef]

71. Skein, M.; Duffield, R.; Kelly, B.T.; Marino, F.E. The effects of carbohydrate intake and muscle glycogen content on self-paced intermittent-sprint exercise despite no knowledge of carbohydrate manipulation. Eur. J. Appl. Physiol. 2012, 112, 2859-2870. [CrossRef] 
72. Heil, D.P. Acid-base balance and hydration status following consumption of mineral-based alkaline bottled water. J. Int. Soc. Sports Nutr. 2010, 7, 29. [CrossRef] [PubMed]

73. Wynn, E.; Krieg, M.-A.; Aeschlimann, J.-M.; Burckhardt, P. Alkaline mineral water lowers bone resorption even in calcium sufficiency: Alkaline mineral water and bone metabolism. Bone 2009, 44, 120-124. [CrossRef] [PubMed]

74. Inbar, O.; Amon, E. A new field-test for the assessment of the human anaerobic and repeated sprints capability-reliability and validity. Harefuah 2016, 155, 335-339, 388. [PubMed]

75. Semenick, D. Anaerobic testing: Practical applications. Strength Cond. J. 1984, 6, 45.

76. Zagatto, A.M.; Beck, W.R.; Gobatto, C.A. Validity of the running anaerobic sprint test for assessing anaerobic power and predicting short-distance performances. J. Strength Cond. Res. 2009, 23, 1820-1827. [CrossRef]

77. Girard, O.; Brocherie, F.; Millet, G.P. Effects of altitude/hypoxia on single- and multiple-sprint performance: A comprehensive review. Sports Med. 2017, 47, 1931-1949. [CrossRef]

78. Gastin, P.B. Energy system interaction and relative contribution during maximal exercise. Sports Med. 2001, 31, 725-741. [CrossRef]

79. Calbet, J.A.L.; de Paz, J.A.; Garatachea, N.; Cabeza de Vaca, S.; Chavarren, J. Anaerobic energy provision does not limit Wingate exercise performance in endurance-trained cyclists. J. Appl. Physiol. 2003, 94, 668-676. [CrossRef]

80. Ogawa, T.; Ohba, K.; Nabekura, Y.; Nagai, J.; Hayashi, K.; Wada, H.; Nishiyasu, T. Intermittent short-term graded running performance in middle-distance runners in hypobaric hypoxia. Eur. J. Appl. Physiol. 2005, 94, 254-261. [CrossRef]

81. Duffield, R.; Dawson, B.; Goodman, C. Energy system contribution to 400-metre and 800-metre track running. J. Sports Sci. 2005, 23, 299-307. [CrossRef]

82. Stewart, P.A. Independent and dependent variables of acid-base control. Respir. Physiol. 1978, 33, 9-26. [CrossRef]

(C) 2020 by the authors. Licensee MDPI, Basel, Switzerland. This article is an open access article distributed under the terms and conditions of the Creative Commons Attribution (CC BY) license (http://creativecommons.org/licenses/by/4.0/). 